\title{
Nutritional status of Fishermen Communities: validation of conventional methods with discriminant function analysis
}

\author{
Baidyanath $\mathrm{Pal}^{1}$, Babulal Seal ${ }^{2}$ and Subrata K. Roy ${ }^{1}$ \\ ${ }^{1}$ Indian Statistical Institute, Biological Anthropology Unit, 203, B.T.Road, Kolkata \\ E-mail: baidya.isi@gmail.com, rsubrata@isical.ac.in \\ ${ }^{2}$ Burdwan University Department of Statistics Burdwan, West Bengal \\ E-mail: babulal_seal@yahoo.com
}

\begin{abstract}
Keywords: Malnutrition, Anthropometry, Discriminant Analysis, Eigen Value, Canonical correlation, Wilk's Lambda
\end{abstract}

\begin{abstract}
Anthropological methods of assessing nutritional status of adults have been reinvestigated. Objective of the study is to detect the predictor variables that discriminate for under nutrition or Chronic Energy Deficiency (CED) by two conventional methods e.g. Body Mass Index (BMI) and Mid Upper Arm Circumference (MUAC). Discriminant function analysis was used to build valid and accurate predictive model for evaluating nutritional status. Anthropometric measurements were collected using standard techniques and used as independent variables. Recommended cut-off values of BMI and MUAC was used for evaluating nutritional status. The extent of CED (BMI < 18.5) was found $43.50 \%$ and prevalence of under-nutrition in terms of MUAC (MUAC $<23.0 \mathrm{~cm}$ for Male and $<22.0 \mathrm{~cm}$ for Female) was 21.7\%. Discriminant function analysis reveals that $85.7 \%$ and $72.0 \%$ individuals were classified correctly in terms of nutritional status. Therefore, BMI is the good indicator for detecting malnutrition. Fat mass discriminates between groups.
\end{abstract}

\section{Introduction}

Under-nutrition or malnutrition is considered as a major public health problem and is a significant area of concern in developing countries (Schofield and Ashworth 1996; Antwi 2008; Khor 2008) like India. India is still one of the poor countries in the world with a total population of more than a billion (World Bank 2000). Krishnaswami (2000) observed that, more than half of the world's undernourished individuals live in India.

It is estimated that approximately eight hundred million individuals worldwide are under- nourished, of which 258 million individuals (a little under one third) are concentrated in south Asia (Gaiha 1997). More than 3.6 million mothers and children die each year as a result of malnutrition (Blake et al. 2008).

It has been recognized that the techniques of anthropometry has a long tradition to assess nutritional and health status of adults (Misra et al. 2001; Rao et al. 2006; Bharati et al. 2007; Bisai et al. 2008) because it is universally applicable, inexpensive and non-invasive in nature (WHO, 1995; Ferro-Luzzi et al., 1992; James et al., 1994; Pirlich and Lochs, 2001). Though nutritional status of adults can be evaluated in many ways, one important measure is the calculation of Quetelet index, popularly known as Body Mass Index (BMI), which is the body weight (in $\mathrm{kg}$ ) divided by square of stature (in $\mathrm{m}$ ) (Keys et al., 1972),. BMI is generally considered as a good indicator and used for the assessment of adult nutritional status (Lee \& Nieman, 2003; Khongsdier, 2002), especially in the developing countries (Khongsdier, 2002; Ferro-Luzzi et al., 1992; Shetty \& James, 1994). Nowadays BMI has been widely used for assessing Chronic Energy Deficiency (CED) (Khongsdier, 2002). On the other, Mid Upper Arm Circumference (MUAC) is another important indicator for simple screening of adult nutritional status specifically in developing countries (James et al., 1994), but its cut-points have not been standardized.

Many studies on Indian populations used single method for evaluating malnutrition in different populations living in different regions, which shows significant association between 
malnutrition and anthropometric measurements. To the best of our knowledge, till date we have not encountered any evidence which have established a suitable method for evaluating malnutrition by comparing two or more methods using common predictors of the same population data. Therefore, we have considered two existing methods (BMI and MUAC) to find out the most effective variables for detecting malnutrition.

In view of the above the objective of the present study are as follows:

1. To determine the prevalence of malnutrition on the basis of conventional anthropological methods.

2. To evaluate the best anthropological method

3. To find out the important discrimating variables out of so many anthropometric measurements.

4. To perform a significant statistical model for predicting malnutrition

Studies on nutritional status among adults of fishing community in India more specifically in West Bengal and Orissa are scanty. Thus, the present anthropometric data was collected on the adults belonging to fishing community living at Digha (West Bengal) and Udaypur (Odissa). With this background information, the present study is carried out.

\section{Material and Methods}

\section{Study population:}

The data of the present study was part of an larger ongoing project on health and nutrition. The fishing community was chosen for its numerical dominance in the area. It had been observed that the children and women of the community had visible symptoms of under nutrition. Villages were selected on the basis of the occupational homogeneity of the population (the adult males generally practice deep sea fishing). Populations are two rural settlements namely Duttapur and Udaypur were selected purposively. However, other nearby settlements was dominated by other occupational groups. A total of 736 individuals were included in the study aged 18 years and above in both sexes. Explaining the purpose of the study, a complete enumeration of both the villages consisting of 285 households was done. The vast majority of the study populations were illiterate (can not read and write) and belonged to lower economic group (family income less than Rs.1000/= per month equivalent to less than 20\$).

\section{Methods}

\section{Anthropometric measurements and indices:}

The following measurements were obtained from the adult individuals (18 to 65 years of age) of both sexes using the standard protocol and instrument (Weiner and Lourie, 1981) by trained investigators.

Variables included in the analysis

\begin{tabular}{|c|c|c|c|}
\hline Sl.No. & Name of the variables & Abbreviation of the variables & Unit of the variable \\
\hline 1. & Age & Age & Years \\
\hline 2. & Sex & Sex & Male/Female \\
\hline 3. & Mid Upper Arm Circumference & MUAC & Centimeter $(\mathrm{cm})$ \\
\hline 4. & Biacromial diameter & Bad & Centimeter $(\mathrm{cm})$ \\
\hline 5. & Biilac diameter & Bid & Centimeter $(\mathrm{cm})$ \\
\hline 6. & Anterior-posterior chest & Apc & Centimeter $(\mathrm{cm})$ \\
\hline 7. & Transverse chest & Tvc & Centimeter $(\mathrm{cm})$ \\
\hline
\end{tabular}




\begin{tabular}{|c|c|c|c|}
\hline 8. & Chest circumference normal & Ccn & Centimeter $(\mathrm{cm})$ \\
\hline 9. & Waist circumference & Wc & Centimeter $(\mathrm{cm})$ \\
\hline 10. & Hip circumference & Hipc & Centimeter $(\mathrm{cm})$ \\
\hline 11. & Skindfolf biceps & Skb & Centimeter $(\mathrm{cm})$ \\
\hline 12. & Skinfold triceps & Skt & Millimeter $(\mathrm{mm})$ \\
\hline 13. & Skinfold subscapular & Sks & Millimeter $(\mathrm{mm})$ \\
\hline 14. & Skinfold suprailliac & Ski & Millimeter $(\mathrm{mm})$ \\
\hline 15. & Skinfold abdomain & Ska & Millimeter $(\mathrm{mm})$ \\
\hline 16. & Skinfold calf & Skc & Millimeter $(\mathrm{mm})$ \\
\hline 17. & Fat mass & Fm & Kilogram $(\mathrm{Kg})$ \\
\hline 18. & Fat percentages & Fp & Kilogram $/ \mathrm{Meter}\left(\mathrm{kg} / \mathrm{m}^{2}\right)$ \\
\hline 19. & Body Mass Insex & BMI & \\
\hline
\end{tabular}

Conventional methods for assessing Nutritional status through anthropometric measurements $\mathrm{BMI}=$ Weight $\left(\right.$ in $\mathrm{Kg}$.) $/$ Height $\left(\right.$ in meter $\left.^{2}\right)$

WHO (2004) have made a recommendation of BMI Cut-off points as follows:

\begin{tabular}{|lr|}
\hline Over weight & $(\geq 25.00)$ \\
\hline Normal weight & $(18.50-24.99)$ \\
\hline Under weight & $(<18.5)$ \\
\hline Mild thinness & $(17.00-18.49)$ \\
\hline Moderate thinness & $(16.00-16.99)$ \\
\hline Severe thinness & $(<16.0)$ \\
\hline
\end{tabular}

MUAC (Mid Upper Arm Circumference) the absolute values are used as cut-off points

Classification of Mid Upper Arm Circumference (MUAC) (James W.P.T. et al., 1994)

\begin{tabular}{llll}
\hline Under nutrition & Male & $<23.0$ & Female $<22.0$ \\
Normal & Male & $\geq 23.0$ & Female $\geq 22.0$
\end{tabular}

\section{Statistical Methods: Discriminant Function Analysis}

\section{Justification:}

Receiver operating characteristic (ROC) analysis was performed to examine the concordance among predictors using the status of malnutrition of dependent variable. ROC analysis for predictors were not better than chance of discriminating between groups of dependent variable. For this reason stepwise discriminant analysis was adopted. It is useful for situation in which to build a predictive model of group membership based on observed characteristics of each case. The target of discriminant analysis is to identify the independent variables that have a strong relationship to the group membership in the category of dependent variable. The technique provides a linear combination of the predictors. The discriminant function creates the maximum difference between group memberships in the categorical dependant variable.

\section{Assumptions:}

1. Each predictor variables is normally distributed.

2. Each group or category is well defined, clearly differentiated from any other group(s) and natural. 
3. There exists a linear relationship between pairs of independent variable.

4. Homogeneity of variance among the groups.

Classification of Body Mass Index (BMI):

Classification

Cut-off points of BMI $\left(\mathrm{kg} / \mathrm{m}^{2}\right)$

Chronic Energy Deficiency (CED)

Normal

Over weight $\leq 18.49$

$18.50-24.99$

$\geq 25.00$

We consider the above cut-off points of BMI and followed the World Health Organization's (2004) classification of the public health problem of low BMI, based on adult population world-wide. This classification categorizes according to percentage of a population with $\mathrm{BMI}<18.5$. In this study, to measure the under nutrition we used two sets of dependent variables i.e. Mid Upper Arm Circumference (MUAC) and Body Mass Index (BMI) have two categories (under-nutrition say malnutrition and normal) and three categories (Chronic Energy Deficiency say Malnutrition, normal and over weight) respectively. The independent variables are Age, Sex, Bid, Bad, Apc, Tvc, Ccn, Wc, Hipc, Skb, Skt, Sks, Ski, Ska, Skc, Fp and Fm.

\section{Results:}

Table 1 provides descriptive statistics of independent variables for both nutritional assessments. There are unequal means of independent variables in each group of nutritional assessment. Group means indicate how much each variable distinguishes the groups. Comparing mean values in each group, there was very little difference between the groups of MUAC and BMI. Result shows that most of the variables are of homogeneity.

Table 2 represents a one way ANOVA statistical test to the means of the variables and results of discriminant analysis. It is observed from the table of MUAC category, that Wilk's Lambda values of few variables i.e. Cc, Wc, Hipc, Fm and Ccn have lower values $(<0.9)$ than other variables This table contains Wilk's Lambda and F-values of each independent variable of both groups. The lowest Wilks Lambda value indicates best contribution of that independent variable to that discriminatory function, those variables contribute to the discriminant function more than other independent variables. Consequently, these variables take highest F-values. Similar results have been found in BMI variable where Fm, Hipc and Wc, takes least Lambda values which are less than 0.50 and have highest F-values. From the results, having the lowest values 0.855 and 0.486 the independent variables are $\mathrm{Cc}$ and Fm in MUAC and BMI respectively. Moreover, since P-values of the test of each of these predictors are smaller than the level of significance (0.05), these predictors are more significant. These results give strong statistical evidence of significant differences between group means.

Table 3 represents summary of canonical discriminant function which includes the eigen value, percentage of variance and canonical correlation in the functions. Eigen value describes how best discriminating ability the function possesses and larger eigen values indicates more amount of variance shared in the linear combination of variables. In the table there is only one function for MUAC and $100 \%$ of variance is accounted by the function. Canonical correlation is a relation between the discriminant score and the levels of these dependent variables. The higher correlation value means the better function that discriminate the groups. Result shows that eigen value and canonical correlation are 0.23 and 0.43 respectively in MUAC which are comparatively low. In BMI there are two functions in the analysis and function 1 explains $87.4 \%$ variance and function 2 explains only $12.6 \%$ of variance and not useful for discriminating the groups.

Table 4 depicts the test statistics of functions for hypothesis that there is no significant discriminant power in the variables. The Wilk's Lambda is one of the multivariate test statistics which indicates the significant of the function and Chi-Square values are based on the groups 
present in the categorical variables. These results indicate a highly significant function $(\mathrm{P} \leq 0.01)$ and provide the proportion of total variability not explained. So $80 \%$ variability is unexplained in MUAC and $28 \%$ variability is unexplained in BMI. Chi-Square values indicate that the group means appear to differ for both nutritional variables.

Table 5 provides the standardized canonical coefficient of each function of both nutritional variables. It is used to rank the importance of each independent variable according to the magnitude of the coefficients. BMI have more contribution than $\mathrm{Cc}$ in the classification by dependant variable MUAC. Whereas Fm, Cc, Wc, MUAC have positive contribution and Age, Bad, Fp have negative contribution for the classification by BMI, as dependent variable.

Table 6 reveals the non-standardized canonical coefficient which is used in the formula for making the classification in discriminant analysis. Result shows that the variable BMI has most contribution in the classification of dependent variable MUAC whereas, FM has the most contribution when consider BMI as dependent variable. In this case,

$$
\mathrm{D}=0.147 * \mathrm{Cc}+0.334 * \mathrm{BMI}-10.736 \text { for MUAC }
$$

and $\mathrm{D}=-0.018^{*}$ Age $-0.037 *$ Sex $-0.082 * \mathrm{Bad}+0.148 * \mathrm{MUAC}+0.037 * \mathrm{Wc}-0.011^{*} \mathrm{Hipc}$

$$
+0.134 * \mathrm{Cc}-0.01 * \mathrm{Skb}-0.087 * \mathrm{Fp}+0.403 * \mathrm{Fm}-7.493 \text { for BMI }
$$

Table 7 shows the correlation of each independent variable with each discriminate function. In this table BMI have the highest correlation than $\mathrm{Cc}$ with discriminant function 1 in MUAC. On the other hand Fm has the highest value than other independent variables with function 1 in BMI. These results provide another way of indicating the relative importance of the predictors and nutritional variables. Generally with a loading of 0.30 or more is considered to be important in define the discriminate dimension.

Table 8 the function of the group centroid gives the average discriminant score of the group. It is observe that Function 1 separates group mean in dependant variables and group 1 (least value) difference between the other canonical group means in classifying observable.

Table 9 is used to assess how well the Fisher's classification function coefficients are classified between the groups and useful in deciding which variable affects more in the classification. Result shows that Sex, Bad Fm, and Fp have most contributions for malnutrition classification. The coefficients of the independent variables are used to construct a discriminant function for each group, i.e. Malnutrition (CED), Normal and Over Weight where,

For BMI

$$
\begin{aligned}
\text { Malnutrition } & =-696.38+0.37 * \text { age }+70.77 * \mathrm{Sex}+11.25 * \mathrm{Bad}+5.44 * \mathrm{MUAC}+2.41 * \mathrm{Wc} \\
& +5.90 * \mathrm{Hipc}+6.33 * \mathrm{CC}-5.64 * \mathrm{Skb}+11.09 * \mathrm{Fp}-28.30 * \mathrm{Fm}
\end{aligned}
$$

$$
\begin{gathered}
\text { Normal }=-720.65+0.30 * \text { age }+69.23 * \mathrm{Sex}+11.11 * \mathrm{Bad}+5.70 * \mathrm{MUAC}+2.51 * \mathrm{Wc}+5.97 * \mathrm{Hipc} \\
+6.69 * \mathrm{Cc}-5.84 * \mathrm{Skb}+11.43 * \mathrm{Fp}-28.78 * \mathrm{Fm}
\end{gathered}
$$

$$
\begin{aligned}
\text { Over Weight }= & -735.11+0.34 * \text { age }+74.52 * \mathrm{Sex}+10.67 * \mathrm{Bad}+6.48 * \mathrm{MUAC}+2.58 * \mathrm{Wc} \\
& +5.61 * \mathrm{Hipc}+6.96 * \mathrm{Cc}-5.22 * \mathrm{Skb}+9.11 * \mathrm{Fp}-23.54 * \mathrm{Fm}
\end{aligned}
$$

Computing equations (3), (4) and (5) for each case and the case is classified into the equation for which computed value is highest. Suppose equation (3) is highest value then the case is classified into malnutrition.

It has been observed from table 10 that $72.0 \%$ and $85.7 \%$ of overall data was correctly classified by the MUAC and BMI respectively. It has also been noticed that $80.0 \%$ and $69.8 \%$ were correctly classified in two groups of MUAC and $90.0 \%, 81.8 \%$ and $95.0 \%$ were correctly classified in three groups of BMI respectively. This result is rather satisfactory for MUAC. Thus the accuracy of the lassification may hence be considered better BMI categories than MUAC categories. 
Table 1: Descriptive statistics in each independent variable for different categories of nutritional variables.

\begin{tabular}{|c|c|c|c|c|c|c|c|c|c|c|c|c|}
\hline \multirow{3}{*}{$\begin{array}{c}\text { Varia- } \\
\text { bles }\end{array}$} & \multicolumn{4}{|c|}{ MUAC Categories } & \multicolumn{6}{|c|}{ BMI Categories } & \multirow{2}{*}{\multicolumn{2}{|c|}{ otal }} \\
\hline & \multicolumn{2}{|c|}{ Under Nutrition } & \multicolumn{2}{|c|}{ Normal } & \multicolumn{2}{|c|}{ CED } & \multicolumn{2}{|c|}{ Normal } & \multicolumn{2}{|c|}{ Over Weight } & & \\
\hline & Mean & S D & Mean & S D & Mean & S D & Mean & S D & Mean & S D & Mean & S D \\
\hline Age & 34.04 & 14.78 & 35.40 & 12.03 & 34.53 & 13.61 & 35.25 & 11.85 & 41.40 & 12.12 & 35.11 & 12.68 \\
\hline $\mathrm{Bad}$ & 33.39 & 2.99 & 34.69 & 2.70 & 33.75 & 2.76 & 34.78 & 2.70 & 37.46 & 2.80 & 34.41 & 2.81 \\
\hline Bid & 24.38 & 1.55 & 25.17 & 1.87 & 24.50 & 1.93 & 25.26 & 1.59 & 27.70 & 1.26 & 25.00 & 1.83 \\
\hline Apc & 15.60 & 1.65 & 16.71 & 2.01 & 15.72 & 1.75 & 16.88 & 1.86 & 20.03 & 1.93 & 16.47 & 1.99 \\
\hline Tvc & 22.33 & 1.98 & 23.47 & 2.19 & 22.38 & 1.90 & 23.70 & 2.02 & 27.42 & 2.38 & 23.23 & 2.19 \\
\hline $\mathrm{Ccn}$ & 74.45 & 4.31 & 79.29 & 6.15 & 74.56 & 4.25 & 80.45 & 5.07 & 93.43 & 6.65 & 78.24 & 6.13 \\
\hline $\mathrm{Wc}$ & 62.43 & 5.39 & 68.62 & 7.07 & 62.56 & 4.76 & 70.18 & 5.81 & 85.15 & 6.41 & 67.27 & 7.20 \\
\hline Hipc & 77.91 & 3.39 & 82.50 & 5.47 & 77.91 & 3.41 & 83.71 & 4.31 & 95.31 & 6.24 & 81.50 & 5.43 \\
\hline $\mathrm{Cc}$ & 27.63 & 2.01 & 30.12 & 2.62 & 28.01 & 2.04 & 30.52 & 2.19 & 36.17 & 2.58 & 29.58 & 2.70 \\
\hline Skb & 2.75 & 0.98 & 3.89 & 2.21 & 2.84 & 1.05 & 4.07 & 2.16 & 8.08 & 3.69 & 3.64 & 2.06 \\
\hline Skt & 6.60 & 2.81 & 8.39 & 4.52 & 6.55 & 2.92 & 8.85 & 4.61 & 14.34 & 5.30 & 8.00 & 4.27 \\
\hline Sks & 8.70 & 2.80 & 11.72 & 5.09 & 8.78 & 2.98 & 12.41 & 4.91 & 20.84 & 5.76 & 11.06 & 4.85 \\
\hline Ski & 6.36 & 2.81 & 9.51 & 5.22 & 6.41 & 2.82 & 10.26 & 5.04 & 19.18 & 6.28 & 8.83 & 4.97 \\
\hline Ska & 8.43 & 3.77 & 12.55 & 6.50 & 8.56 & 3.62 & 13.39 & 6.13 & 26.58 & 6.83 & 11.65 & \begin{tabular}{|l|}
6.24 \\
\end{tabular} \\
\hline Skc & 6.17 & 2.65 & 8.28 & 4.71 & 6.26 & 3.02 & 8.75 & 4.66 & 14.70 & 6.92 & 7.83 & 4.43 \\
\hline $\mathrm{Fp}$ & 15.99 & 4.85 & 19.88 & 6.60 & 15.23 & 4.63 & 21.63 & 5.97 & 28.77 & 5.45 & 19.04 & 6.46 \\
\hline Fm & 6.45 & 2.18 & 9.67 & 4.04 & 6.20 & 1.92 & 10.66 & 3.26 & 19.68 & 3.02 & 8.97 & 3.95 \\
\hline MUAC & & & & & 22.30 & 1.69 & 24.21 & 1.69 & 29.41 & 2.28 & 23.53 & 2.18 \\
\hline BMI & 17.15 & 1.38 & 19.66 & 2.34 & & & & & & & 19.11 & 2.41 \\
\hline
\end{tabular}

Table 2:Test of equality of group mean in each independent variable of both nutritional variables.

\begin{tabular}{|c|c|c|c|c|c|c|}
\hline \multirow{2}{*}{ Variables } & \multicolumn{3}{|c|}{ MAUC } & \multicolumn{3}{|c|}{ BMI } \\
\cline { 2 - 7 } & Wilks' Lambda & $\mathrm{F}(\mathrm{df}=1,734)$ & Sig. & Wilks' Lambda & $\mathrm{F}(\mathrm{df}=2,733)$ & Sig. \\
\hline Age & 0.998 & 1.43 & 0.232 & 0.992 & 2.84 & 0.059 \\
\hline Sex & 0.989 & 7.99 & 0.005 & 0.989 & 4.11 & 0.017 \\
\hline Bad & 0.964 & 27.49 & 0.00 & 0.935 & 25.45 & 0.00 \\
\hline Bid & 0.968 & 24.00 & 0.00 & 0.898 & 41.73 & 0.00 \\
\hline Apc & 0.947 & 41.12 & 0.00 & 0.830 & 75.25 & 0.00 \\
\hline Tvc & 0.954 & 35.37 & 0.00 & 0.810 & 85.69 & 0.00 \\
\hline Ccn & 0.894 & 87.00 & 0.00 & $\mathbf{0 . 6 0 6}$ & 237.84 & 0.00 \\
\hline MUAC & & & & $\mathbf{0 . 6 1 2}$ & 232.51 & 0.00 \\
\hline BMI & $\mathbf{0 . 8 1 5}$ & 166.82 & 0.00 & & & \\
\hline Wc & $\mathbf{0 . 8 7 4}$ & 105.49 & 0.00 & $\mathbf{0 . 5 5 9}$ & 288.98 & 0.00 \\
\hline Hipc & $\mathbf{0 . 8 7 8}$ & 101.97 & 0.00 & $\mathbf{0 . 5 4 4}$ & 307.12 & 0.00 \\
\hline Cc & $\mathbf{0 . 8 5 5}$ & 124.32 & 0.00 & $\mathbf{0 . 6 2 5}$ & 219.57 & 0.00 \\
\hline Skb & 0.948 & 40.06 & 0.00 & 0.785 & 100.13 & 0.00 \\
\hline Skt & 0.970 & 22.50 & 0.00 & 0.869 & 55.43 & 0.00 \\
\hline Sks & 0.934 & 52.07 & 0.00 & 0.751 & 121.28 & 0.00 \\
\hline Ska & 0.926 & 58.71 & 0.00 & 0.696 & 160.18 & 0.00 \\
\hline Ski & 0.932 & 53.90 & 0.00 & 0.734 & 132.86 & 0.00 \\
\hline Skc & 0.961 & 29.47 & 0.00 & 0.857 & 61.19 & 0.00 \\
\hline Fp & 0.938 & 48.35 & 0.00 & 0.700 & 156.80 & 0.00 \\
\hline Fm & 0.887 & 93.85 & 0.00 & $\mathbf{0 . 4 8 6}$ & 388.16 & 0.00 \\
\hline
\end{tabular}


Table 3: Summary of canonical discriminant functions of nutritional variables.

\begin{tabular}{|c|c|c|c|c|c|}
\hline & Function & Eigenvalue & \% of Variance & Cumulative \% & Canonical \\
\hline \multirow{2}{*}{ MUAC } & 1 & .25 & 100.0 & 100.0 & .45 \\
\hline \multirow{2}{*}{ BMI } & 1 & 1.74 & 84.5 & 84.5 & .80 \\
\cline { 2 - 6 } & 2 & .32 & 15.5 & 100.0 & .49 \\
\hline
\end{tabular}

Table 4: Test statistics Wilk's Lambda of nutritional variables.

\begin{tabular}{|c|c|c|c|c|c|}
\hline & Test of Function (s) & Wilks' Lambda & Chi-square & df & Sig. \\
\hline \multirow{2}{*}{ MUAC } & 1 & .80 & 161.97 & 2 & .00 \\
\hline \multirow{2}{*}{ BMI } & 1 through 2 & .28 & 936.82 & 20 & .00 \\
\cline { 2 - 6 } & 2 & .76 & 201.68 & 9 & .00 \\
\hline
\end{tabular}

Table 5: Standardized canonical discriminant function coefficient.

\begin{tabular}{|c|c|c|c|}
\hline \multirow{3}{*}{ Variables } & MUAC & \multicolumn{2}{|c|}{ BMI } \\
\cline { 2 - 4 } & Function & 1 & 2 \\
\cline { 2 - 4 } & 1 & -0.229 & 0.544 \\
\hline Age & & -0.018 & 0.937 \\
\hline Sex & & -0.222 & -0.054 \\
\hline Bad & & 0.199 & -0.173 \\
\hline Wc & & -0.043 & -0.431 \\
\hline Hipc & & 0.287 & -0.253 \\
\hline Cc & 0.368 & -0.018 & 0.420 \\
\hline Skb & & -0.469 & -3.592 \\
\hline Fp & & 1.109 & 2.740 \\
\hline Fm & & 0.253 & 0.059 \\
\hline MUAC & & & \\
\hline BMI & 0.726 & \multicolumn{2}{|c|}{} \\
\hline
\end{tabular}

Table 6: Canonical discriminant function coefficients of nutritional variables.

\begin{tabular}{|c|c|c|c|}
\hline \multirow{2}{*}{ Variables } & MUAC & \multicolumn{2}{|c|}{ BMI } \\
\cline { 2 - 4 } & Function & 1 & 2 \\
\cline { 2 - 4 } & 1 & -0.082 & -0.020 \\
\hline Bad & & 0.037 & -0.032 \\
\hline Wc & & -0.011 & -0.107 \\
\hline Hipc & & 0.134 & -0.118 \\
\hline Cc & 0.147 & -0.010 & 0.230 \\
\hline Skb & & -0.087 & -0.663 \\
\hline Fp & & 0.403 & 0.995 \\
\hline Fm & & 0.148 & 0.035 \\
\hline MUAC & & & \\
\hline BMI & 0.334 & -7.493 & 12.770 \\
\hline Constant & -10.736 & \multicolumn{2}{|c|}{} \\
\hline
\end{tabular}

Table 7: Structure matrix of nutritional variables.

\begin{tabular}{|c|c|c|c|}
\hline \multirow{2}{*}{ Variables } & MUAC & \multicolumn{2}{|c|}{ BMI } \\
\cline { 2 - 4 } & Function & \multicolumn{2}{|c|}{ Function } \\
\cline { 2 - 4 } & 1 & 1 & 2 \\
\hline Cc & 0.828 & $0.586^{*}$ & -0.019 \\
\hline Hipc & & $0.692^{*}$ & -0.101 \\
\hline Fm & & $0.778^{*}$ & -0.107 \\
\hline
\end{tabular}




\begin{tabular}{|c|c|c|c|}
\hline Wc & & $0.671^{*}$ & -0.110 \\
\hline Fp & & $0.478^{*}$ & -0.305 \\
\hline Skb & & $0.392^{*}$ & 0.132 \\
\hline Bad & & $0.199^{*}$ & 0.022 \\
\hline Sex & & -0.079 & 0.032 \\
\hline Age & & 0.058 & $0.075^{*}$ \\
\hline MUAC & & $0.602^{*}$ & $0 . .093$ \\
\hline BMI & 0.959 & & \\
\hline
\end{tabular}

Table 8: Function of group centriods of nutritional variables.

\begin{tabular}{|c|c|c|c|c|c|}
\hline \multirow{2}{*}{ Function } & \multicolumn{2}{|c|}{ MUAC Categories } & \multicolumn{3}{c|}{ BMI Categories } \\
\cline { 2 - 6 } & Under Nutrition & Normal & Chronic Energy Deficiency & Normal & Over Weight \\
\hline 1 & -0.942 & 0.262 & -1.243 & 0.734 & 5.339 \\
\hline 2 & & & 0.361 & -0.417 & 2.481 \\
\hline
\end{tabular}

Table 9: Classification functions coefficients of nutritional variables.

\begin{tabular}{|c|c|c|c|c|c|}
\hline & \multicolumn{2}{|c|}{ MUAC Categories } & \multicolumn{3}{c|}{ BMI Categories } \\
\cline { 2 - 6 } & Under Nutrition & Normal & Cronic Energy Deficiency & Normal & Over \\
\hline Cc & 4.047 & 4.224 & 6.33 & 6.69 & 6.96 \\
\hline Age & & & 0.370 & 0.301 & 0.342 \\
\hline Sex & & & $\mathbf{7 0 . 7 7 2}$ & $\mathbf{6 9 . 2 3 3}$ & 74.521 \\
\hline Bad & & & $\mathbf{1 1 . 2 5 5}$ & $\mathbf{1 1 . 1 0 6}$ & 10.673 \\
\hline Wc & & & 2.408 & 2.506 & 2.583 \\
\hline Hipc & & & 5.904 & 5.966 & 5.606 \\
\hline Skb & & & -5.640 & -5.838 & -5.219 \\
\hline Fp & & & $\mathbf{1 1 . 0 8 5}$ & $\mathbf{1 1 . 4 2 9}$ & 9.108 \\
\hline Fm & & & $\mathbf{- 2 8 . 3 0 2}$ & $\mathbf{- 2 8 . 2 7 9}$ & -23.539 \\
\hline MUAC & & 5.439 & 5.704 & 6.484 \\
\hline BMI & 0.683 & 1.085 & & & \\
\hline Constant & -62.458 & -74.974 & -696.376 & -720.650 & -735.107 \\
\hline
\end{tabular}

Table 10: Classification results of nutritional variables.

\begin{tabular}{|c|c|c|c|c|c|c|}
\hline \multirow{2}{*}{\multicolumn{3}{|c|}{ MUAC Categories }} & \multicolumn{3}{|c|}{ Predicted Group Membership } & \multirow{3}{*}{$\begin{array}{c}\text { Total } \\
160\end{array}$} \\
\hline & & & Under Nutrition & Normal & Over Weight & \\
\hline \multirow{4}{*}{ Original } & \multirow[t]{2}{*}{ Count } & Under Nutrition & 128 & 32 & & \\
\hline & & Normal & 174 & 402 & & 576 \\
\hline & \multirow[t]{2}{*}{$\%$} & Under Nutrition & 80.0 & 20.0 & & 100.0 \\
\hline & & Normal & 30.2 & 69.8 & & 100.0 \\
\hline \multirow{4}{*}{$\begin{array}{c}\text { Cross } \\
\text { validation }\end{array}$} & \multirow[t]{2}{*}{ Count } & Under Nutrition & 126 & 34 & & 160 \\
\hline & & Normal & 174 & 402 & & 576 \\
\hline & \multirow[t]{2}{*}{$\%$} & Under Nutrition & 78.8 & 21.2 & & 100.0 \\
\hline & & Normal & 30.2 & 69.8 & & 100.0 \\
\hline \multicolumn{7}{|c|}{ BMI Categories } \\
\hline \multirow[t]{6}{*}{ Original } & \multirow[t]{3}{*}{ Count } & Chronic Energy Deficiency & 288 & 32 & 0 & 320 \\
\hline & & Normal & 59 & 324 & 13 & 396 \\
\hline & & Over Weight & 0 & 1 & 19 & 20 \\
\hline & \multirow[t]{3}{*}{$\%$} & Chronic Energy Deficiency & 90.0 & 10.0 & .0 & 100.0 \\
\hline & & Normal & 14.9 & 81.8 & 3.3 & 100.0 \\
\hline & & Over Weight & .0 & 5.0 & 95.0 & 100.0 \\
\hline
\end{tabular}




\begin{tabular}{|c|c|c|c|c|c|c|}
\hline $\begin{array}{c}\text { Cross } \\
\text { validation }\end{array}$ & Count & Chronic Energy Deficiency & 286 & 34 & 0 & 320 \\
\cline { 3 - 6 } & & Normal & 61 & 321 & 14 & 396 \\
\cline { 2 - 6 } & \multirow{3}{*}{$\%$} & Over Weight & 0 & 1 & 19 & 20 \\
\cline { 3 - 6 } & & Chronic Energy Deficiency & 89.4 & 10.6 & .0 & 100.0 \\
\cline { 3 - 6 } & & Normal & 15.4 & 81.1 & 3.5 & 100.0 \\
\cline { 2 - 6 } & Over Weight & .0 & 5.0 & 95.0 & 100.0 \\
\hline
\end{tabular}

\section{Discussion:}

In recent years the assessment of malnutrition using body mass index (BMI) has been done in third world countries including India (Bose et al., 2007; Gogoi and Sengupta, 2002; Khongsdier, 2002; Sahani, 2003). There are many studies which show the decreasing trend of anthropometric values with advancement of age (McLorg, 2005; Miccozi and Harris, 1990). The mean age 35.11 years $(\mathrm{SD}=12.68$ years $)$ indicates the present study population as young adults. The mean BMI $19.11\left(\mathrm{SD}=2.41 \mathrm{~kg} / \mathrm{m}^{2}\right.$ ) for individual of this population is lower than other populations (Bose et al., 2007). Results of present study on lowest mean value in most of the anthropometric measurements are also in concordance with studies from other parts of the world (McLorg 2005; Miccozi and Harris 1990; Strickland and Ulijaszek, 1993).

Discriminant Analysis was carried out to predict whether the population was malnutrition or not and detect the significant variables causes of malnutrition. In this study predictor variables were Age, Sex, Bad, Bid, Apc, Tvc, Ccn, Wc, Hipc, Cc, Skb, Skt, Sks, Ski, Ska, Skc, Fm, Fp where BMI and MUAC are dependant variables. For this analysis apply Stepwise Discriminant Analysis to derermine the best combinations of the independent variables. Only two independent variables i.e. $\mathrm{Cc}$ and BMI were included in analysis while MUAC was dependent variable. On the other side best subset among the independent variables i.e. Age, Sex, Bad, Cc, Wc, Hipc, Skb, Fm, Fp and MUAC were included in analysis while BMI was dependent variable. In the present study, prevalence of CED (43.5\%) indicates the poor health of the study population in terms of BMI which is in concordance with other studies from India (Bose and Chakraborty, 2005).

The estimated discriminate function correctly classifies about $72.0 \%$ and $85.7 \%$ of original grouped while dependant variables are MUAC and BMI respectively. Since the Dependant variables MUAC and BMI have two and three categories, so there are one and two discriminant functions respectively. The result shows that $100 \%$ variance between groups can be explain by the only function of MUAC. For BMI function 1 is more important than function 2 since maximum variance $(84.5 \%)$ among three groups can be explained by function 1 . The degree of relationship (canonical correlation) between the predictors and groups of dependant variable BMI $(0.80)$ due to function 1 is more than MUAC (0.45). Based on the above results BMI is the better predictor for evaluate malnutrition than MUAC.

Structure matrix suggest that the independent variables Age, Sex, Bad, Cc, Wc, Hipc, Skb, Fm, Fp and MUAC have the most significant relation with function 1. Among those variables MUAC, $\mathrm{Cc}$ and Fm have most positive contribution and rest of the variables have negative contribution for construct the function in the classification of dependent variable BMI.

\section{Conclusion:}

This paper is concerned with anthropometric characteristics and nutritional status of the fishing community of West Bengal and Odisha. It was observed that malnutrition has the highest proportion of correctly classifying than normal in both nutritional variables. Furthermore, BMI has highest percentage of correctly classification than MUAC. Thus BMI should be preferred than MUAC method for evaluating the malnutrition. Result suggest that fat mass has portent discriminator power for evaluate malnutrition. As per discriminant analysis results show that the condition of the population causes severe health problem. An appropriate intervention for improving the nutritional status should be initiated at the local level. 


\section{References}

[1] Antwi, S. 2008. "Malnutrition: Missed opportunities for diagnosis." Ghana Medical Journal 42:101-104.

[2] Bharati, S., M. Pal, B.N. Bhattacharya and P. Bharati. 2007. "Prevalence and causes of chronic energy deficiency and obesity in Indian women." Human Biology 79:395-412.

[3] Bisai, S. and K. Bose. 2008. "Body Mass Index and Chronic Energy Deficiency among Adult Tribal Populations of West Bengal: A Review." Tribes and Tribals 2:87-94.

[4] Blake, R.E., L.H. Allen, Z.A. Bhutta, L.E. Caulfield, M.D. Onis, M. Ezzati, C. Mathers and J. Rivera. 2008. "Maternal and child undernutrition: global and regional exposers and health consequence." Lancet 371:243-260.

[5] Bose, K. and F. Chakraborty. 2005. "Anthropometric characteristics and nutritional Status based on body mass index of adult Bathudis: A tribal population of Keonjhar District, Orissa, India." Asia Pacific Journal of Clinical Nutrition 14: 80-82.

[6] Bose, K., F. Chakraborty and S. Bisai. 2007. "Age trends in anthropometric and body composition characteristics and undernutrition among female Bathudis: A tribal population of Keonjhar district, Orissa, India." Anthropologischer Anzeiger, 65(3): 285-291.

[7] Ferro-Luzzi A, Sette S, Franklin M and James WPT. 1992. A simplified approach of assessing adult chronic deficiency. European Journal of Clinical Nutrition 46:173-186.

[8] Gaiha, R. 1997. "Hunger, undernutrition and poverty in India." Contemporary South Asia 6(2):161-175

[9] Gogoi, G. and S. Sengupta. 2002. "Body mass index among the Dibongiya Deoris of Assam, India." Journal of Human Ecology 13:271-273.

[10]James, W.P.T., C.G.N. Mascie-Taylor, N.G. Norgan, B.R. Bristrian, P. Shetty and A. FerroLuzzi. 1994. "The value of arm circumference measurements in assessing chronic energy deficiency in Third World adults." European Journal of Clinical Nutrition 48: 883-894.

[11]Keys, A., F. Fidanza, M.J. Karvonen, N. Kimura and H.L. Taylor. 1972. "Indices of relative weight and obesity." Journal of Chronic Disease 25:329-43.

[12] Khongsdier, R. 2002. "Body mass index and morbidity in adult males of the War Khasi in Northeast India." European Journal of Clinical Nutrition 56:484-489.

[13]Khor, G.L. 2008. "Food-based approaches to combat the double burden among the poor: Challenges in the Asian context." Asia Pacific Journal of Clinical Nutrition 17:S111-S115.

[14] Krishnaswami, K. 2000. "Country profile: India. Nutritional disorders - old and changing." Lancet, 351:1268- 1269.

[15]Lee, R.D. and D.C. Nieman. 2003. "Nutritional Assessment.” McGraw Hill, New York.

[16] McLorg, P.A. 2005. "Anthropometric patterns in middleaged and older rural Yucatec Maya women." Annals of Human Biology 32:487 - 497.

[17] Miccozi, M.S. and T.M. Harris. 1990. "Age variations in the relation of body mass indices to estimates of body fat and muscle mass." American Journal of Physical Anthropology 81:375 379.

[18]Misra, A., R. Sharma, R.M. Pandey and N. Khanna. 2001. "Adverse profile of dietary nutrients, anthropometry and lipids in urban slum dwellers of northern India." European Journal of Clinical Nutrition 55:727-734.

[19]Pirlich, M. and H. Lochs. 2001. "Nutrition in the elderly." Best Practice Research Clinical Gastroenterology 15:869 - 884. 
[20]Rao, K.M., A. Laxmaiah, K. Venkaiah and G.N. Brahmam. 2006. "Diet and nutritional status of adolescent tribal population in nine states of India." Asia Pacific Journal of Clinical Nutrition 15:64-71.

[21] Sahani, R. 2003. "Nutritional and health status of the Jarawas: A preliminary report." Journal of Anthropological Survey of India 52: 47-65.

[22] Schofield, C. and A. Ashworth. 1996. "Why have mortality rates for severe malnutrition remained so high?" Bulletin of World Health Organization 74:223-229.

[23] Shetty, P.S. and W.P.T. James. 1994. "Body Mass Index - A Measure Of Chronic Energy Deficiency In Adults, FAO Food And Nutrition Paper 56," Food and Agricultural Organisation, Rome.

[24] Strickland, S.S. and S.J. Ulijaszek. 1993. "Body mass index, aging and differential reported morbidity in rural Sarawak." European Journal of Clinical Nutrition 47:9-19.

[25] Sudharsanam, M.B. 2006 "Risk Factors for Sick Children in a Fisherman Community in Pondicherry." Indian Journal of Community Medicine 31(4): 308-309.

[26] Weiner, J.S. and J.A. Lourie. 1981. "Practical Human Biology.” London: Academic Press.

[27] World Health Organization. 1990. "Diet, nutrition, and the prevention of chronic disease." Technical Report Series no 797. Geneva: World Health Organization.

[28] World Health Organization. 2004. "WHO expert consultation. Appropriate body-mass index for Asian populations and its implications for policy and intervention strategies." The Lancet363(9403):157-163.

[29] World Health Organization. 1995. "Physical Status: the Use and Interpretation of Anthropometry. Technical Report Series no. 854." World Health Organization, Geneva.

[30] World Bank. 2000. "World Development Report 2000/2001: Attacking Poverty." Oxford University Press, New York. 